\title{
Low Temperature Growth of High-Quality Carbon Nanotubes by Local Surface Joule Heating without Heating Damage to Substrate
}

\author{
Sung-Taek Heo and Dong-Gu Lee ${ }^{\wedge}$ \\ Department of Information and Nano Materials Engineering, Kumoh National Institute of Technology, Gumi, Gyungbuk 730-701, Korea \\ ^e-mail:dglee@kumoh.ac.kr \\ (Received July 22, 2009; Accepted September 10, 2009)
}

\begin{abstract}
In this study, a low temperature growth of high-quality carbon nanotubes on glass substrate using a local surface heating without heating damage to substrate was tried and characterized. The local joule heating was induced to only Ni/Ti metal film on glass substrate by applying voltage to the film. It was estimated that local surface joule heating method could heat the metal surface locally up to around $1200^{\circ} \mathrm{C}$ by voltage control. We could successfully obtain high-quality carbon nanotubes grown at $300^{\circ} \mathrm{C}$ by applying $125 \mathrm{~V}$ for joule heating as same as carbon nanotubes grown at $900^{\circ} \mathrm{C}$.
\end{abstract}

Keywords : Carbon nanotubes, Chemical vapor deposition, CVD, Low temperature growth, Local joule heating

\section{Introduction}

Since their discovery in 1991 [1], carbon nanotubes (CNTs) have excited many researchers owing to their amazing electrical and mechanical properties. They have various applications such as a tip material for field emission device and scanning probe microscope, an intercalation material for Li ion battery, a hydrogen gas storage material for electric vehicles, and so on. But many technical problems also remained because it is not easy to control them due to their small size [2]. Moreover, commercialization would not become active until the techniques for large-amount and low-cost synthesis are developed. Electronic industries have been significantly using transparent glasses or plastics as substrates for flexible displays or other electronic devices. However, theses substrates commonly have low thermal durability. For examples, temperature for polyimide should not exceed $260^{\circ} \mathrm{C}$, and soda-lime glass is also strained at a temperature over $511^{\circ} \mathrm{C}$. One of the most attractive applications of CNTs is an electron emitter for flat panel displays and white light sources using its sharp tip. Since the typical growth temperature of CNTs is around $700 \sim 900^{\circ} \mathrm{C}$ using thermal CVD system [3-5], it is difficult to grow highquality CNTs on glass substrate. In this study, a local surface joule heating by applying voltage to metal film electrode on glass substrate was tried to grow high-quality CNTs on glass without any strains to the substrate.

\section{Experimental}

A patterned $(20 \mathrm{~mm} \times 7 \mathrm{~mm}) \mathrm{Ni} / \mathrm{Ti}$ thin film $(20 \mathrm{~nm} / 200 \mathrm{~nm})$ was sputtered on a glass substrate (PD-200) under constant DC power of $50 \mathrm{~W}$ at working pressure of 5 mTorr. Fig. 1 shows the schematic diagram of a two-temperature zone chemical vapor deposition (CVD) reactor. The first heating zone was maintained at $900^{\circ} \mathrm{C}$ for the decomposition of acetylene $\left(\mathrm{C}_{2} \mathrm{H}_{2}\right)$ gas and the second heating zone was controlled at $400 \sim 500^{\circ} \mathrm{C}$ for the growth of CNTs on glass substrate. Ni film was used as a catalyst for growing CNTs and $\mathrm{Ti}$ film as an electrode for carrying electrical current. The Ni-deposited Ti electrode on glass substrate was placed at the second heating zone with an angle of $15^{\circ}$ to the quartz boat. The Ni/Ti film was contacted to electrical wires coming through electrical feedthrough for applying voltage.

The chamber was pumped down to around $20 \mathrm{mTorr}$ and Ar gas $(200 \mathrm{sccm})$ was flowed into a CVD quartz reactor in order to prevent the oxidation of the $\mathrm{Ni}$ catalytic film during heating of the chamber. Then the $\mathrm{Ni} / \mathrm{Ti}$ film on glass substrate was pretreated using $\mathrm{NH}_{3}$ gas with a flow rate of $20 \mathrm{sccm}$ for $10 \mathrm{~min}$ before growing the CNTs. The $\mathrm{NH}_{3}$ pretreatment causes the continuous $\mathrm{Ni}$ catalytic film to be formed as the discontinuous nano-islands and to make $\mathrm{Ni}$

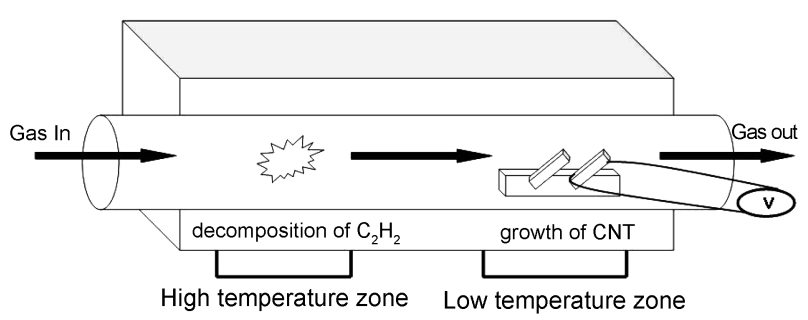

Fig. 1. Schematic diagram of two-temperature zone CVD system used for the growth of carbon nanotubes. 
surface activated for CNT growth.

The CNTs were grown using $\mathrm{C}_{2} \mathrm{H}_{2} / \mathrm{NH}_{3}$ gas with a flow rate of $20 / 60 \mathrm{sccm}$ for $10 \mathrm{~min}$ at an atmospheric condition. After the growth, the reactor was cooled down to room temperature under Ar gas.

Morphology of Ni catalyst layer and the grown CNTs was examined by a scanning electron microscopy (SEM, JEOL JSM-7000F). Raman spectroscope was used to analyze the crystallinity of the grown CNTs through atom-atom bonding characteristics. The Raman peaks of CNTs normally show D peak $\left(1350 \mathrm{~cm}^{-1}\right)$ and $\mathrm{G}$ peak $\left(1590 \mathrm{~cm}^{-1}\right)$. D peak indicates the crystal disorder of graphite such as amorphous carbons and $\mathrm{G}$ peak indicates crystalline graphite. The degree of graphitic ordering in the carbon deposits was compared from the peak integrated intensity ratio of the $\mathrm{G}$ band to D band of CNTs.

\section{Results and Discussion}

\subsection{Temperature estimation of $\mathrm{Ni} / \mathrm{Ti}$ layer according to local surface joule heating}

Thermal CVD has become an important technique in the fabrication of CNT emitters, because it enables CNTs to be grown vertically-aligned on a large patterned substrate using lithography technique [6,7]. However, there still exists a critical problem on how to reduce the processing temperature for preventing substrate damage, especially for glass substrate because growth temperature of CNTs is too high for glass. Therefore we tried a local surface heating only on electrode without heating a whole body of glass substrate to grow high-quality carbon nanotubes. When applying voltage to $\mathrm{Ni} / \mathrm{Ti}$ films for joule heating, it is very difficult to measure the actual temperatures of Ti electrode because the electrode dimension is too small and the applied voltage induces misleading read from thermocouple. Therefore, the surface temperature was estimated as follows. The actual sample of a Ni/Ti film on glass was laid on a hotplate and the electrical resistance of the $\mathrm{Ni} / \mathrm{Ti}$ film was measured with increasing temperature of hotplate. The empirical equation of temperature vs. electrical resistance was established by curve fitting.

$$
\mathrm{T}\left({ }^{\circ} \mathrm{C}\right)=684 \times\left(\mathrm{R}_{\mathrm{T}} / \mathrm{R}_{\mathrm{O}}\right)+\left(2.364 \times 10^{-5}\right) \times\left(\mathrm{R}_{\mathrm{T}} / \mathrm{R}_{\mathrm{O}}\right)^{2}-631
$$

$\mathrm{R}_{\mathrm{T}}$ is the electrical resistance $(\Omega)$ of $\mathrm{Ni} / \mathrm{Ti}$ electrode at a certain temperature $(T)$ and $R_{O}$ is resistance value at $50^{\circ} \mathrm{C}$ as a reference. Then a certain voltage was actually applied to the sample in the CVD growth chamber for surface joule heating during CVD growth. By an applied voltage, a local surface heating on $\mathrm{Ni} / \mathrm{Ti}$ film occurred, leading to change in electrical current, from which resistance values were obtained. From the measured $\left(\mathrm{R}_{\mathrm{T}} / \mathrm{T}_{\mathrm{O}}\right)$ value (shown in Table 1 ) and the above equation, we noticed that the surface temperature of $\mathrm{Ni} / \mathrm{Ti}$ film could be raised up to as high as $1185^{\circ} \mathrm{C}$ by applying a voltage of $125 \mathrm{~V}$, which is the growth temperature region of
Table. 1. Estimated Temperature of Ni/Ti Electrode Film with Applied Voltage at a Growth Temperature of $300^{\circ} \mathrm{C}$

\begin{tabular}{ccccc}
\hline $\mathrm{V}($ volt $)$ & $\mathrm{I}(\mathrm{A})$ & $\mathrm{R}(\Omega)$ & $\mathrm{R}_{\mathrm{T}} / \mathrm{R}_{\mathrm{O}}$ & $\mathrm{T}\left({ }^{\circ} \mathrm{C}\right)$ \\
\hline 50 & 0.022 & 2272 & 1.646 & 497 \\
70 & 0.029 & 2414 & 1.749 & 567 \\
100 & 0.033 & 3030 & 2.196 & 873 \\
125 & 0.040 & 3125 & 2.264 & 920 \\
150 & 0.041 & 3658 & 2.651 & 1185 \\
\hline \multicolumn{1}{l}{} & & & \\
& & & & \\
& & &
\end{tabular}

Fig. 2. Carbon nanotube sample grown on a glass substrate without any distortions.
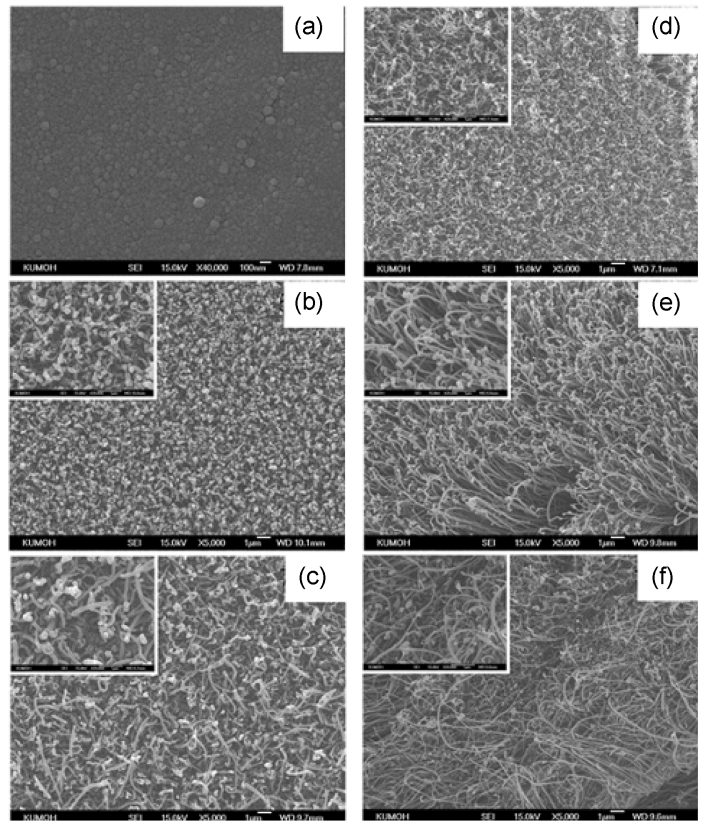

Fig. 3. FE-SEM images of carbon nanotubes grown on $20 \mathrm{~nm}$ $\mathrm{Ni}$ catalyst at $300^{\circ} \mathrm{C}$ for $10 \mathrm{~min}$ with an applied voltage of (a) $0 \mathrm{~V}$, (b) $50 \mathrm{~V}$, (c) $70 \mathrm{~V}$, (d) $100 \mathrm{~V}$, (e) $125 \mathrm{~V}$, and (f) $150 \mathrm{~V}$ (the insets are magnified images).

CNTs. However, any deformations or distortions were not found on glass substrate as shown in Fig. 2.

\subsection{Synthesis of carbon nanotubes by local surface heating}

Fig. 3 shows the growth of carbon nanotubes at a growth temperature of $300^{\circ} \mathrm{C}$ with an increase in applied voltage for local heating. Whereas carbon nanotubes did not grow when no voltage was applied as shown in fig. 3(a), it can be seen from fig. 3(b) (f) that as the applied voltage was increased, 


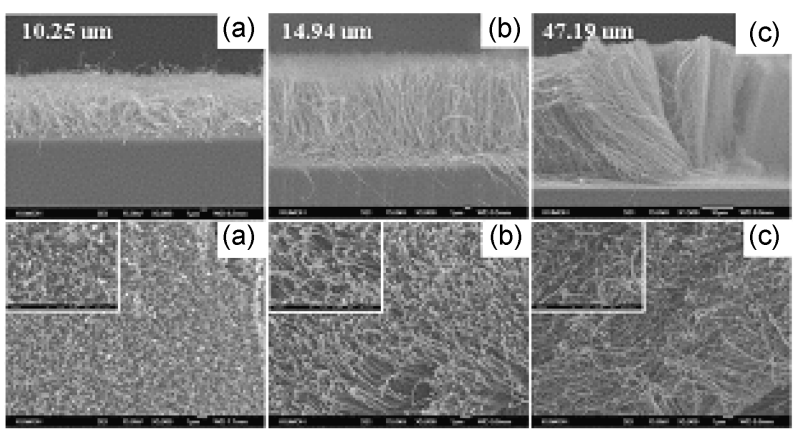

Fig. 4. FE-SEM images of carbon nanotubes grown on $20 \mathrm{~nm}$ $\mathrm{Ni}$ catalyst at $300^{\circ} \mathrm{C}$ for $10 \mathrm{~min}$ with an applied voltage of (a) $100 \mathrm{~V}$, (b) $125 \mathrm{~V}$, and (c) $150 \mathrm{~V}$.

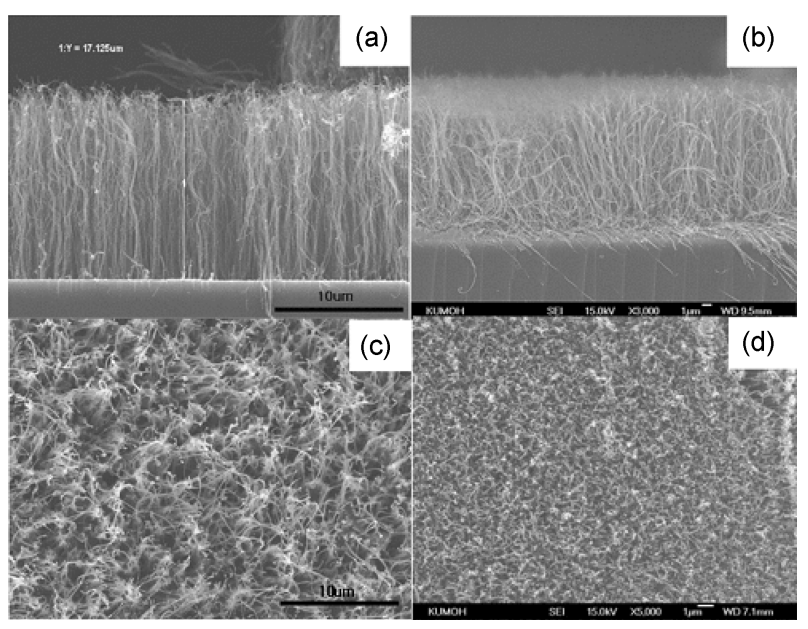

Fig. 5. FE-SEM images of CNTs grown at (a)(c) $900^{\circ} \mathrm{C}$ without local heating and (b)(d) $300^{\circ} \mathrm{C}$ with local surface heating by applied voltage of $125 \mathrm{~V}$.

carbon nanotubes were grown more soundly and densely, and the length and diameter of CNTs were increased with good uniformity. We proved that carbon nanotubes can be grown at low growth temperature as low as $300^{\circ} \mathrm{C}$ using extra local surface heating.

Fig. 4 shows changes in the length and density of carbon nanotubes with increasing applied voltage. CNT length and density were larger at higher voltage. It could be seen that big differences in the length of CNTs between $100 \mathrm{~V}$ and $150 \mathrm{~V}$ might result from temperature difference, which is estimated to be around $700^{\circ} \mathrm{C}$ as shown in Table 1 . Temperature difference in Ni catalyst metal surface affects the diffusion rate of activated carbon species dissociated from $\mathrm{C}_{2} \mathrm{H}_{2}$ into the catalyst metal, resulting in CNT growth rate.

Fig. 5(b, d) are photos of carbon nanotubes grown at $300^{\circ} \mathrm{C}$ with local surface heating and fig. $5(\mathrm{a}, \mathrm{c})$ are photos of carbon nanotubes grown at $900^{\circ} \mathrm{C}$ by conventional thermal CVD method for comparison. CNT growth occurred on $\mathrm{Ni}$ catalyst metal of $20 \mathrm{~nm}$ thickness under the condition of $\mathrm{NH}_{3}$ / $\mathrm{C}_{2} \mathrm{H}_{2}(20 \mathrm{sccm} / 60 \mathrm{sccm})$ mixture in this experiment. Little differences in CNT morphology could be found between them.

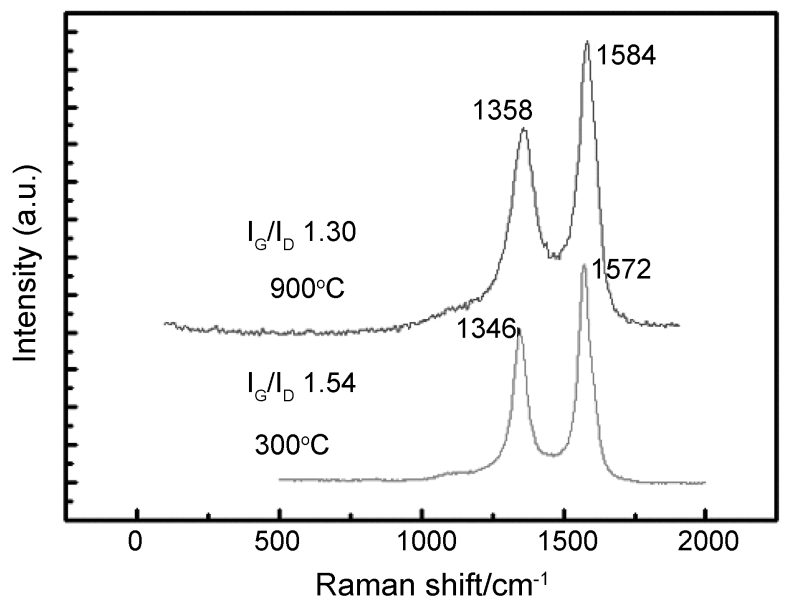

Fig. 6. Raman spectra of carbon nanotubes chemically vapordeposited at (a) $900^{\circ} \mathrm{C}$ without local heating and (b) $300^{\circ} \mathrm{C}$ with local surface heating by applying $125 \mathrm{~V}$.

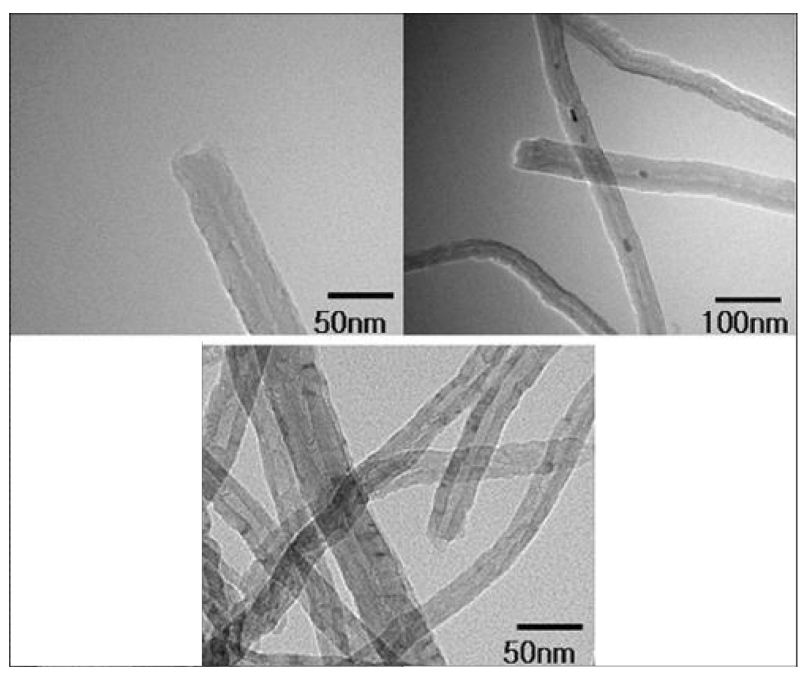

Fig. 7. TEM images of carbon nanotubes grown by CVD with local heating method.

Fig. 6 shows the comparison result of Raman spectra for crystallinity of CNTs made by the two growth methods. As shown in the figure, there were not many differences in crystallinity. The crystal quality of CNTs using local heating from $\mathrm{I}_{\mathrm{G}} / \mathrm{I}_{\mathrm{D}}$ ratio comparison is surprisingly a little bit higher than that of CNTs by the conventional CVD growth method.

Finally, CNTs grown by CVD with a local heating method were observed by transmission electron microscopy as shown in Fig. 7. Typical CNT morphologies were observed and sometimes Ni catalyst metal particles (black dots) were found inside CNT tubes around base regions of CNT tubes. This base growth mechanism may be from the enhanced adhesion of Ni particles to $\mathrm{Ti}$ film due to interdiffusion of $\mathrm{Ni}$ and $\mathrm{Ti}$ during local surface heating. The diameters of the carbon nanotubes were around $20 \sim 50 \mathrm{~nm}$.

It is expected that carbon nanotubes can be grown under 
temperatures lower than $300^{\circ} \mathrm{C}$ by applying higher voltage and that CNT growth on plastic substrate will work well in the next experiment.

\section{Conclusions}

From the above results, we successfully grew high-quality CNTs on glass substrate using conventional CVD method even at a temperature of as low as $300^{\circ} \mathrm{C}$ through surface heating method. It was possible to heat locally the metal film surface up to around $1200^{\circ} \mathrm{C}$ with an applied voltage of $150 \mathrm{~V}$ without any distortions to glass substrate. It is expected that this results give possibility to grow CNTs even on flexible plastic substrate.

\section{Acknowledgement}

The authors would like to acknowledge the financial supports by Research Fund, Kumoh National Institute of Technology.

\section{References}

[1] Iijima, S Nature, 1991, 354, 56.

[2] Saito, R; Fujita, M.; Dresselhaus, G.; Dresselhaus, M. S. Appl. Phys. Lett. 1992, 60, 2240.

[3] Kang, H. S.; Yoon, H. J.; Kim, C.O.; Hong, J. P.; Han, I. T.; Cha, S. N.; Song, B. K.; Jung, J. E.; Lee, N. S.; Kim, J. M. Chem. Phys. Lett. 2001, 349, 196.

[4] Lee, C. J.; Park, J.; Han, S.; Ihm, J. Chem. Phys. Lett. 2001, $337,398$.

[5] Han, J. H.; Choi, S. H.; Lee, T. Y.; Yoo, J. B.; Park, C. Y.; Jung, T. W.; Kim, H. J.; Park, Y. J.; Han, I. T.; Heo, J. N.; Lee, J. H.; Yu, S. G.; Yi, W. K.; Park, G. S.; Lee, N. S.; Kim, J. M. J. Vac. Sci. Technol. B 2003, 21(3), 1120.

[6] Ando, Y.; Zhao, X.; Kataura, H.; Achiba, Y.; Kaneto, K.; Tsuruta, M.; Uemura, S.; Iijima, S. Diamond Rel. Mater. 2000, 9, 847.

[7] Thess, A.; Lee, R.; Nikolaev, P.; Dai, H.; Petit, P.; Robert, J.; Xu, C.; Lee, Y. H.; Kim, S. G.; Rinzler, A. G.; Colbert, D. T.; Scuseria, G. E.; Tomanek, D.; Fischer, J. E.; Smalley, R. E. Science 1996, 273, 483. 